\title{
The Effect of Education Through Cyberspace on Breastfeeding Efficacy of Primiparous Women in Shahroud in 2018: A Randomized Clinical Trial
}

\author{
Zeinab Heidari ${ }^{1}$, Gulbahar akhoundzadeh ${ }^{* 2}$, Hamid Hojjati
}

1. MSc Student, Department of Nursing, Aliabad Katoul Branch, Islamic Azad University, Aliabad Katoul, Iran

2. Assistant Professor, Department of Nursing, Aliabad Katoul Branch, Islamic Azad University, Aliabad Katoul, Iran

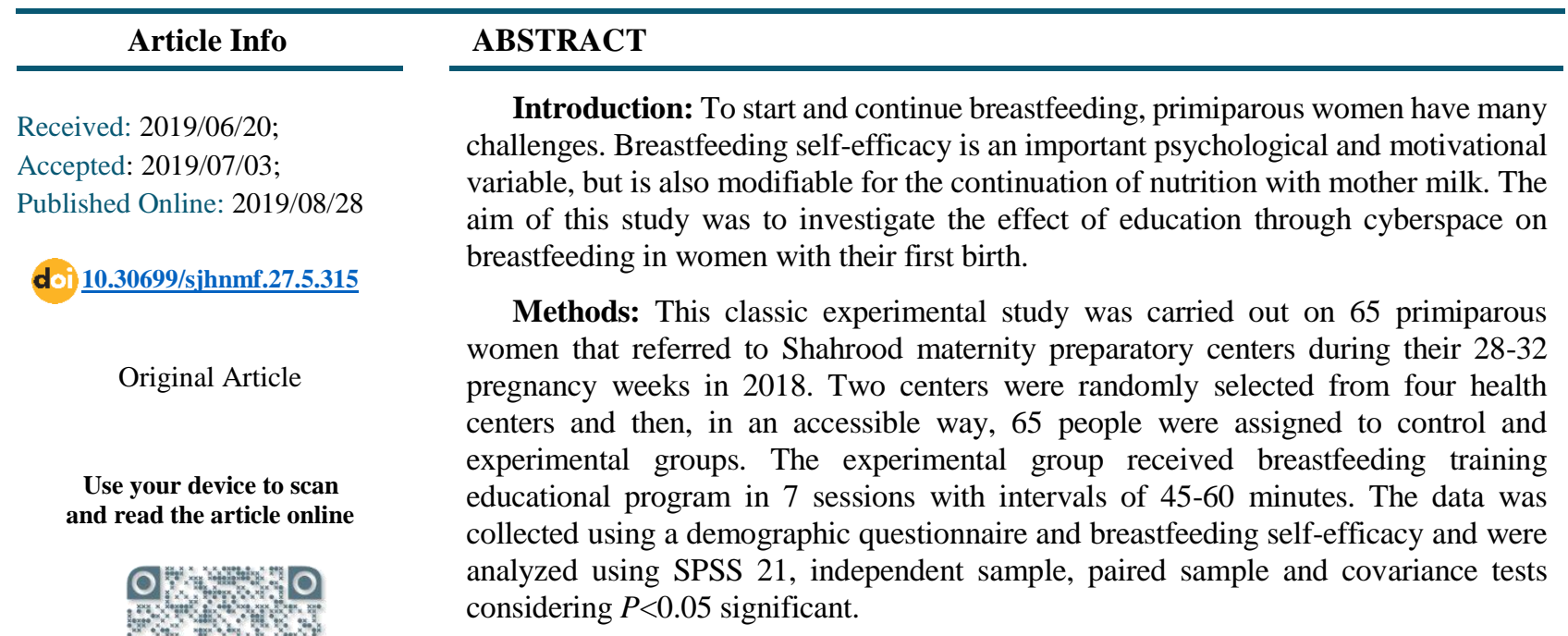

Results: The independent t-test did not show a significant difference between the mean self-efficacy of the two groups before and after the intervention $(P=0.1)$, but there was a significant difference between the two groups after the intervention $(P<0.01)$.

Conclusion: According to the results, education through cyberspace can be used as a new and effective method for self-efficacy of breastfeeding in primiparous women. Therefore, it seems that mothers' education can improve the factors related to lactation self-efficacy and subsequently improve breastfeeding status.

Keywords: Education, Pregnant women, Breastfeeding, Self-efficacy

Corresponding Information:

Gulbahar akhoundzadeh, Assistant Professor, Department of Nursing, Aliabad Katoul Branch, Islamic Azad University, Aliabad Katoul, Iran. E-mail: g_akhoundzadeh@aliabadiau.ac.ir

Copyright $@$ 2019, This is an original open-access article distributed under the terms of the Creative Commons Attribution-noncommercial 4.0 International License which permits copy and redistribution of the material just in noncommercial usages with proper citation.

\section{How to Cite This Article:}

Heydari Z, Akhondzadeh G, Hojati H. The Effect of Education Through Cyberspace on Breastfeeding Efficacy of Primiparous Women in Shahroud in 2018: A Randomized Clinical Trial. Avicenna J Nurs Midwifery care. 2019; 27 (5) :315-325 
تأثير آموزش از طريق فضاى مجازى بر خودكار آمدى شيردهى زنان نخستزاى شهرستان شاهرود يك مطالعة كار آزمايى بالينى تصادفى سودي

زينب حيدرى'، گلبهار آخوندزاده**، حميد حجتى

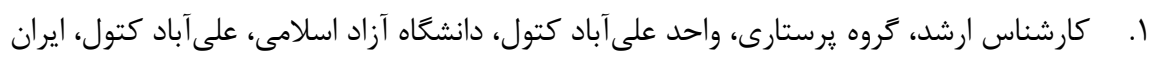

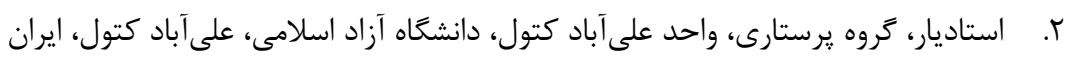

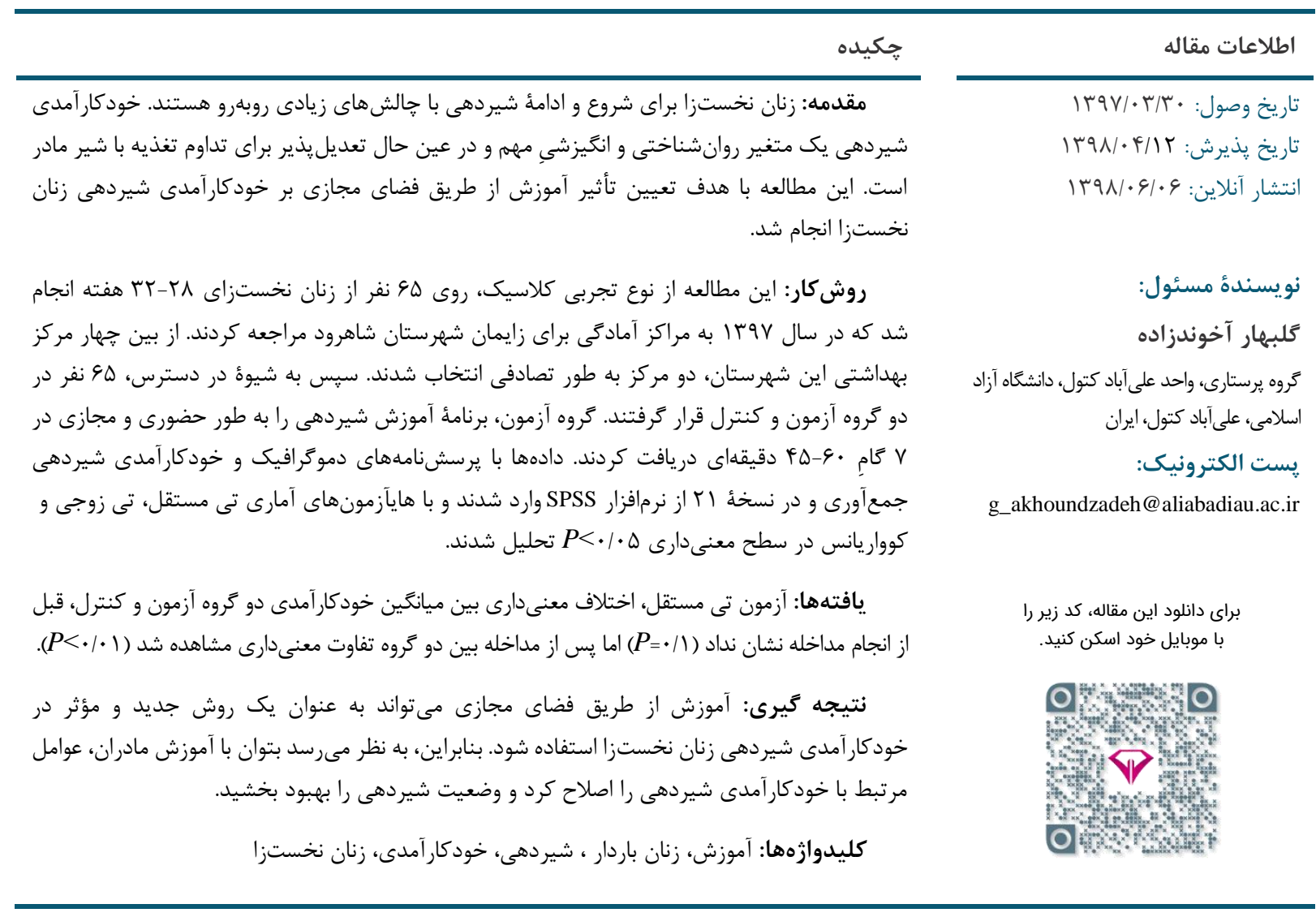

\section{مقدمه}

ناكهانى نوزاد، كاهش ديابت نوع اول و دوم، كاهش سرطانهاى دوران كودكى، كاهش ميزان عفونت كوش ميانى، عفونتهاى

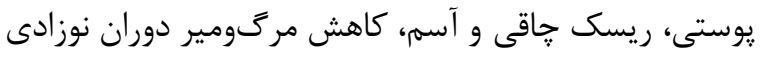
در اثر بيمارىهاى عفونى جزو فوايد كوتاهمدت تغذيه با شير

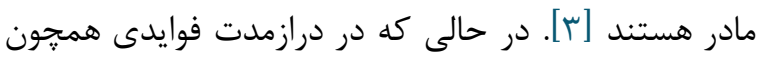

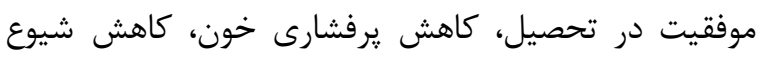

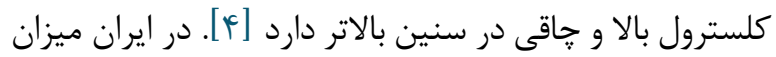

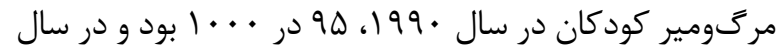

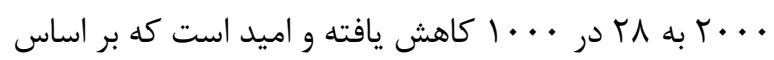

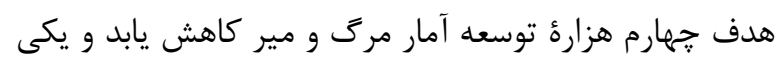
از راهكارهاى اصلى براى اين كاهش، تغذئ انحصارى با با
شير مادر بهترين انتخاب براى منبع تغذىهاى براى شيرخواران و مهمترين عامل در جلوخيرى از بيمارىهاى

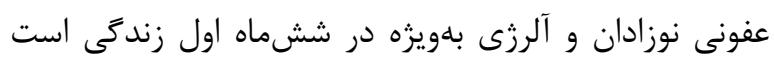

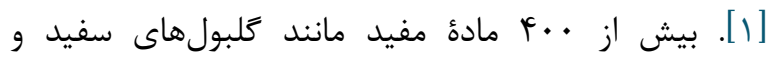
ايمونوگلوبين در شير مادر وجود دارد كه شيرخوار را در برابر مادر

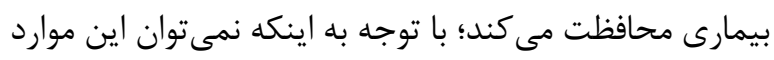

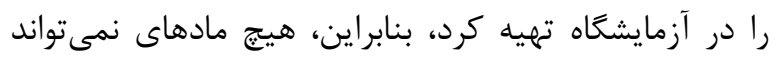
جاى شير مادر را بخيرد [ب]. بنابراين بارزترين و مهمهترين

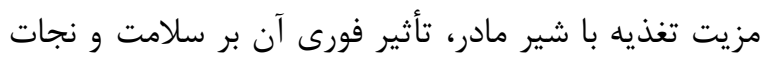
نوزادان است. رشد و تكامل مطلوب نوزاد و كاهش نادي احتمال ابتلا به عفونتهاى تنفسى و گَوارشى، كاهش بروز سندرم مرى 
مىتوانند بر سبك زندىى افراد تأثير بكذارند و باعث جهت-

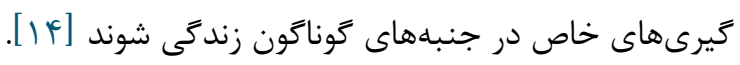

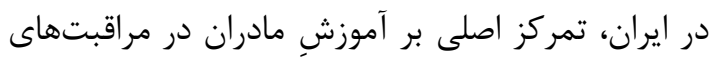

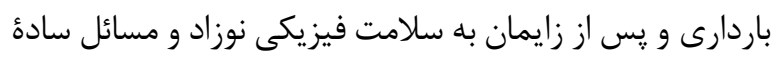

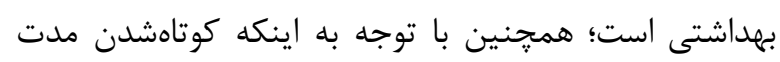

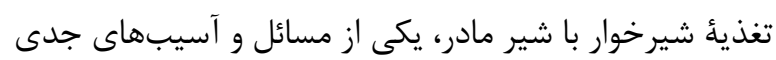

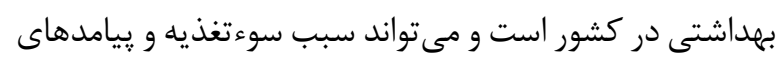

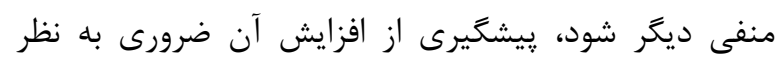

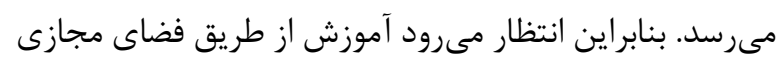

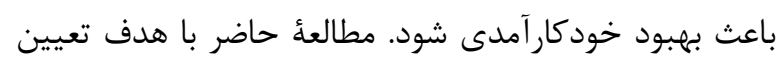

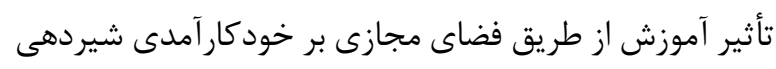

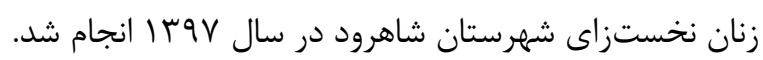

\section{روش كار}

اين يزوهش از نوع تجربى كلاسيك، همراه با دو گروه

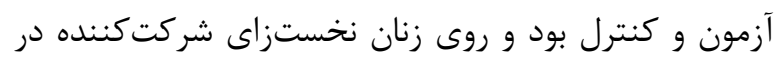

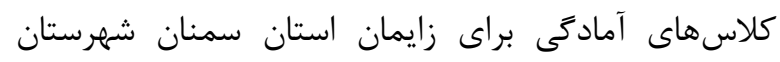

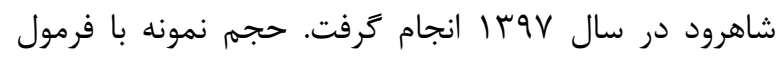

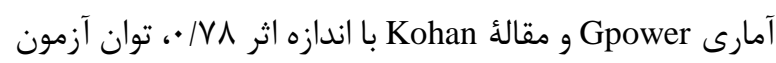

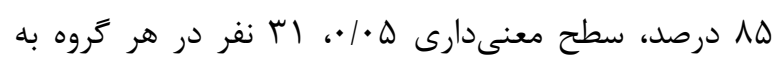

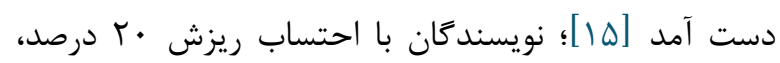

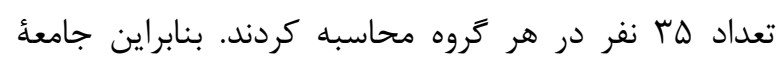

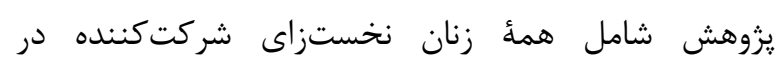

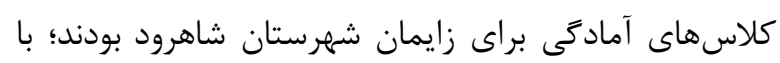

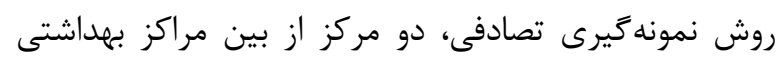

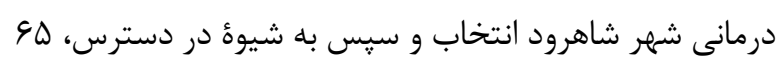

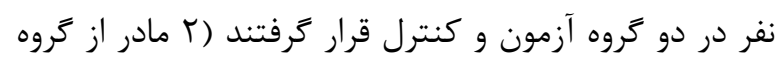

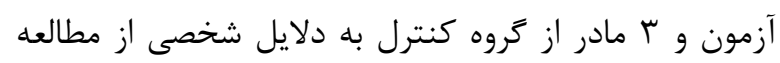

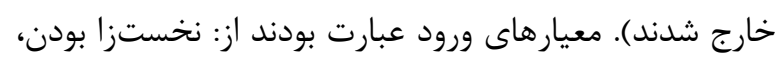

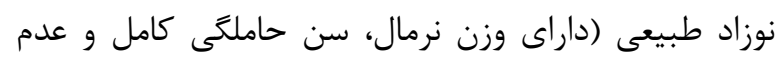

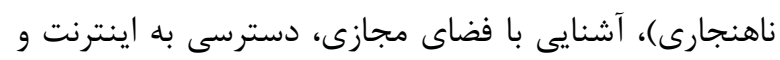

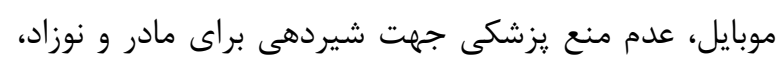

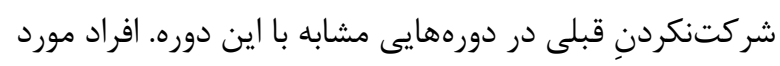

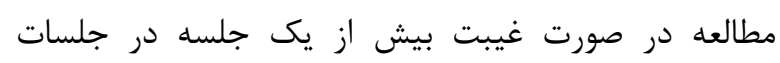
آموزشى، از مطالعه حذف مى مُ ديدند.

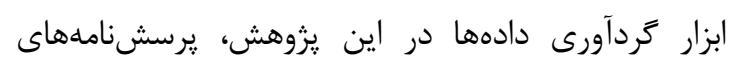

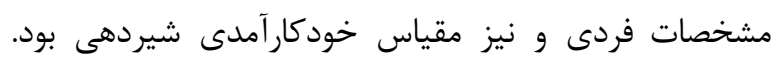

شيرمادر تا ششماهكى است [ه]]. در ايران طبق تزارش وزارت

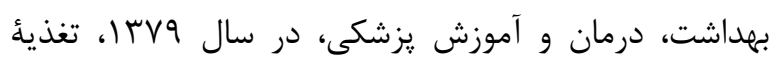

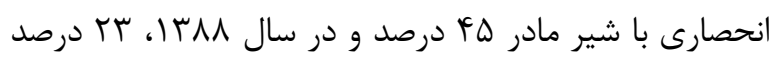

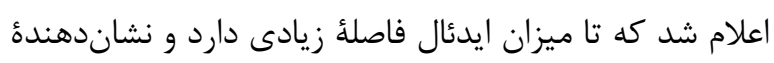

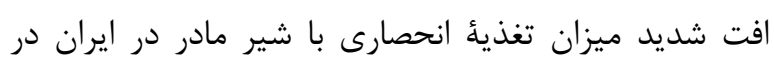
سال هاى اخير است [ع] فئ.

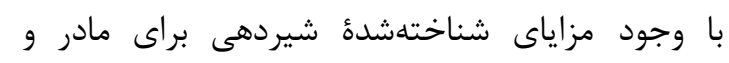

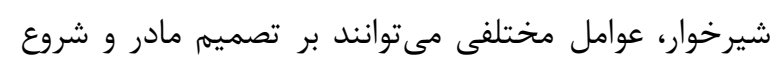

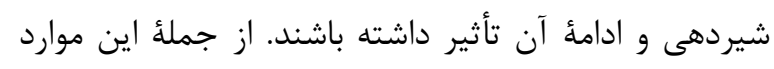

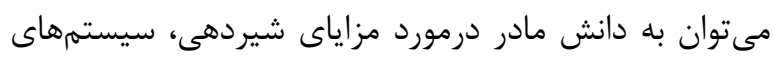

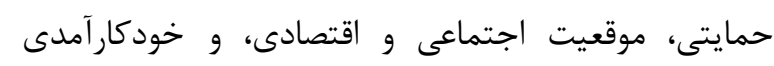

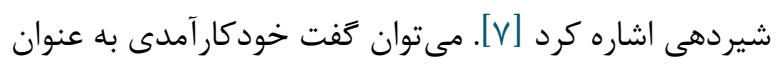

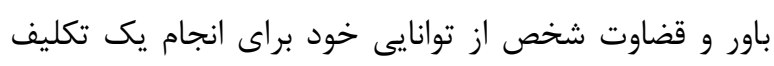
خاص است كه موجب مىشود، رفتار خاصى را با موفقيت اجرا

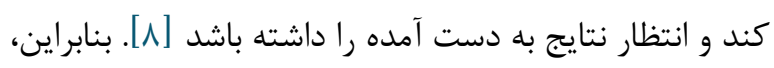

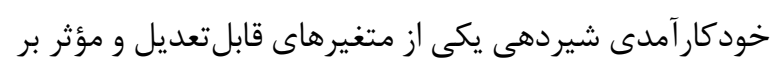

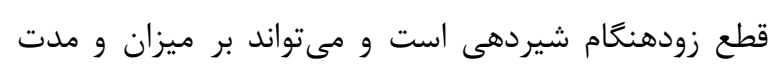

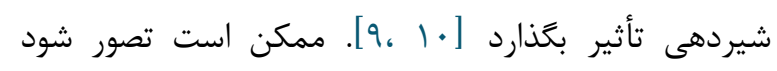

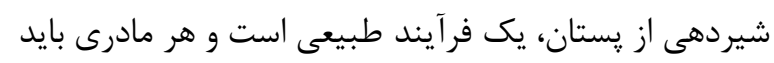

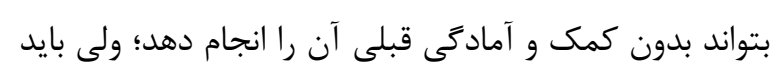

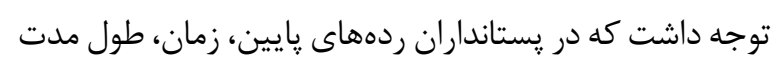

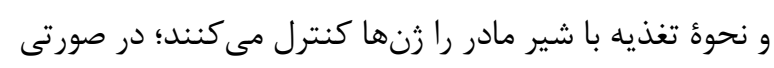
كه در يستانداران ردههاى بالاتر همانند انسان، همأ ائن اين امور

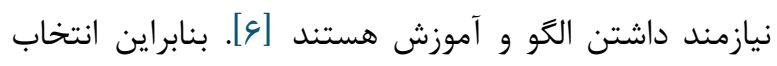

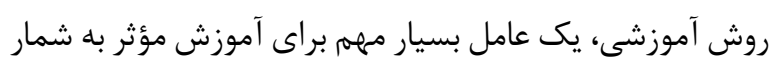

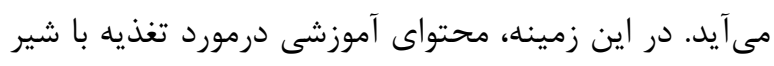

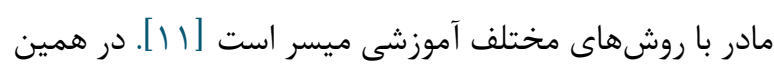

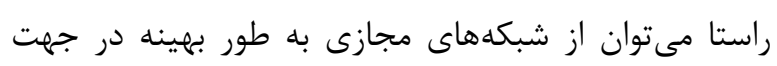

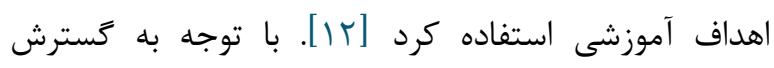
كاربردهاى فناورى اطلاعات و ارتباطات در زندكى استى روزمره،

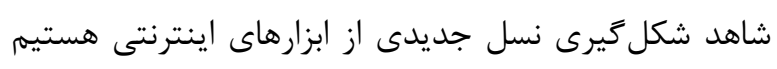

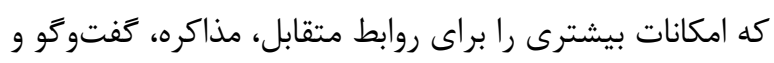

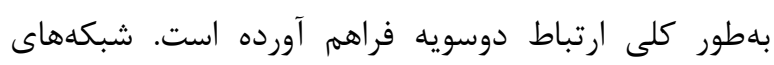

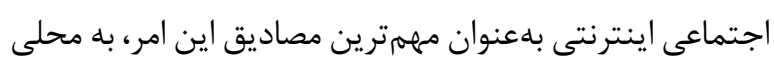

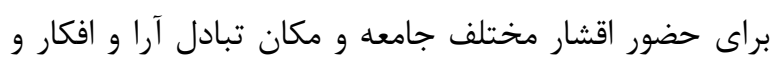

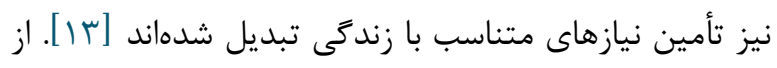

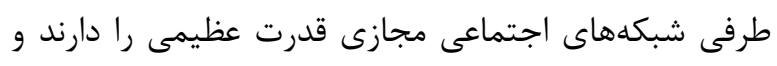


نحوه استفاده از نرمافزار به ايشان ارائه شد.)؛ (ث) كام ينجم شامل

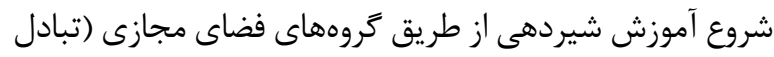

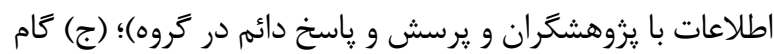

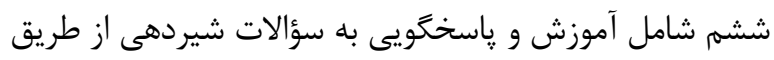
كروه مجازى؛ و (ج) كام هفتم: شامل جمعبندى مباحث كذشته

و ارائُٔ راهكارهايى براى يِيخيرى آموختهها (جدول (1) ).

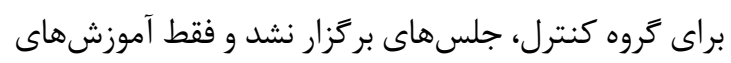
روتين مركز را دريافت كردند. در קايان جلسات آموزشى (جهار

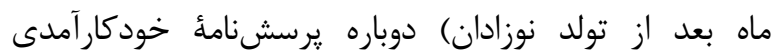

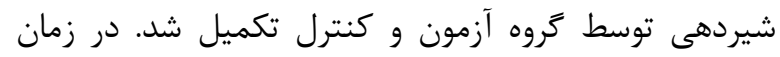

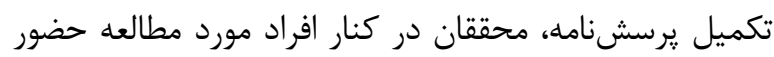
داشتند تا در صورت هركونه ابهام و سوالى، ياسخكو باشند. همجنين وزن نوزادان در بدو تولد و در جهار ماهكَّى در دو كَروه آزمون و كنترل كرفته شد (شكل () ).

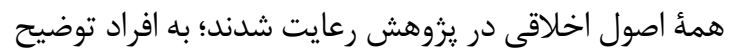

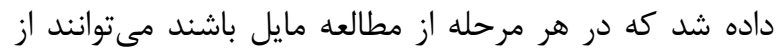

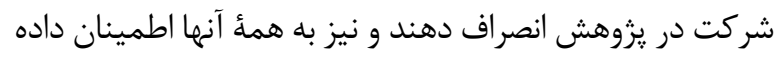

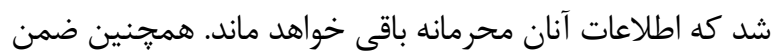
توضيح اهداف يروهش، رضايتنامئ كتبى آكاهانه از نمونهها براى

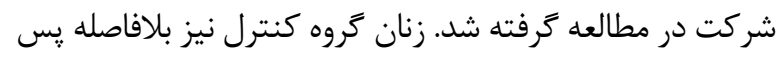
از تكميل يرسشنامه، مورد مشاوره جهت شروع مجدد تغذئ انحصارى با شير مادر توسط محققان قرار گرفتند. در نهايت،

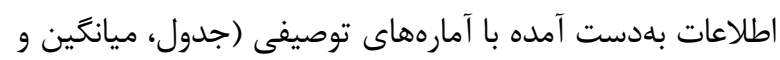

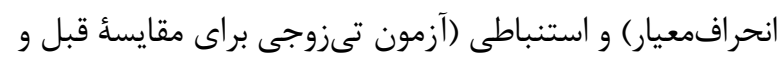

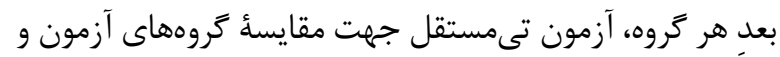

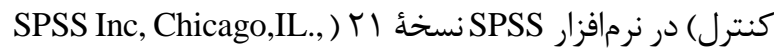

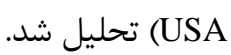

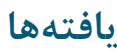

يزوهش حاضر روى •V مادر نخستزا آغاز شد. از •V مادرى

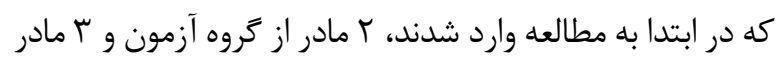
از خروه كنترل به دليل عدم تمايل به ادامه همكارى از مطالعه مارد

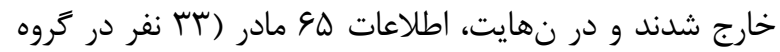

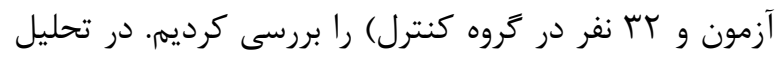

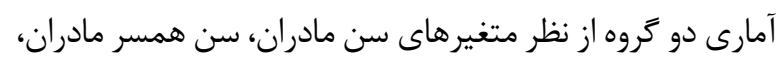

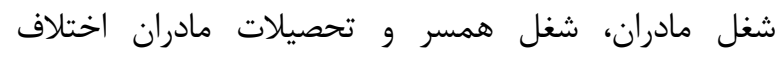
معنى دارى را نشان نداد؛ ولى ميزان تحصيلات همسر مادران در
يرسشنامة اطلاعات دموكرافيك شامل سن، شغل و ميزان تحصيلات والدين، وزن در زمان تولد نوزاد و در \& ماهكَ كونى كودى

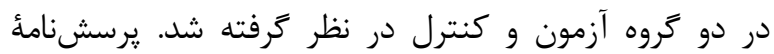

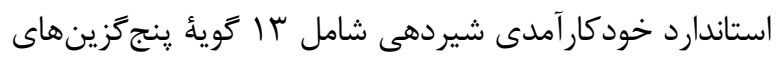
در مقياس ليكرت است كه نكرش و اعتقادات مادر درمورد تغذيه با شير مادر را مىسنجد و همأ كويهها با عبارت لامن هميشه

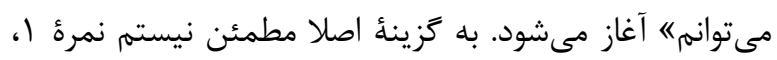
كمى مطمئنم نمرئ ז، تاحدى مطمئنم نمرءٔ זّ، بسيار مطمئنم

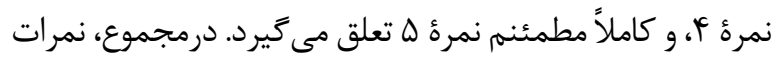

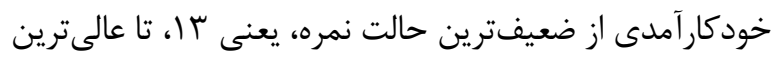

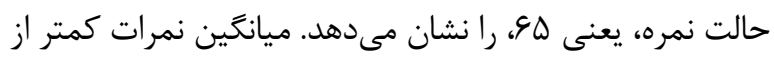

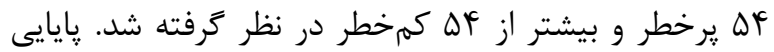

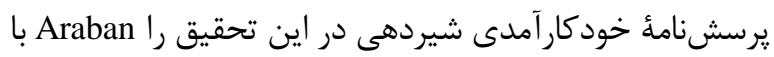

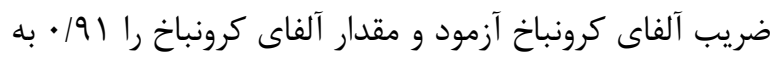

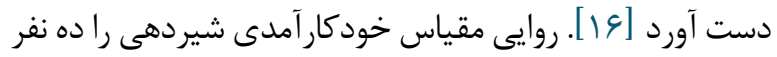

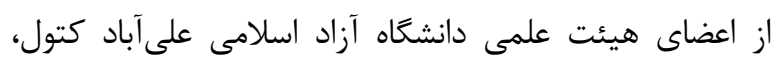

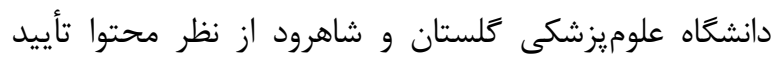

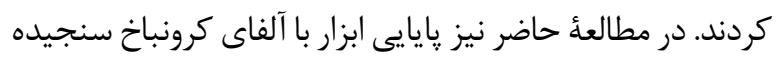
شد و ع/1/ به دست آمد.

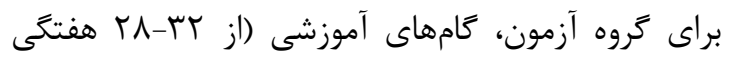

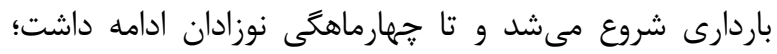

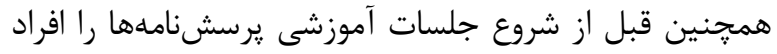

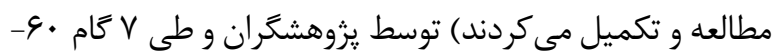

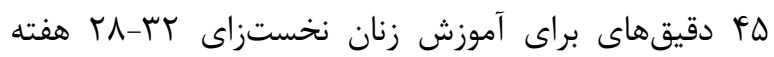
مراجعهكننده در كلاسهاى آمادكى براى زايمان (درمانگاه)

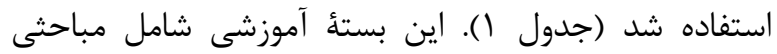

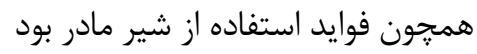
هفت كام ارائهشده به شركت كنندكان عبارت بودند از: (الف)

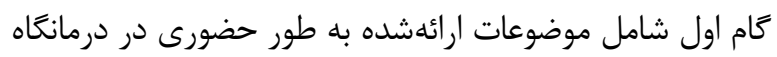

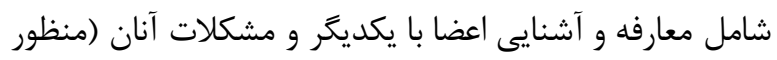

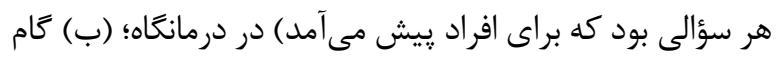

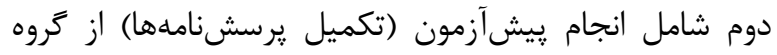

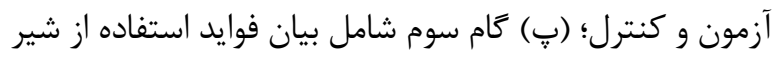

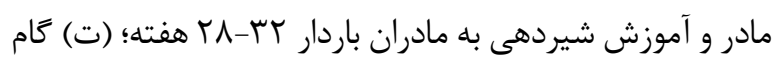

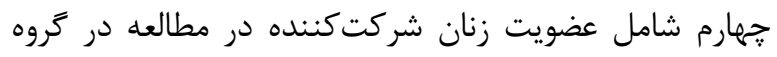

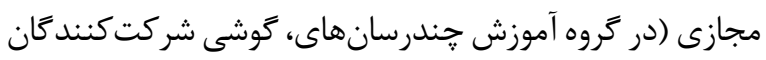

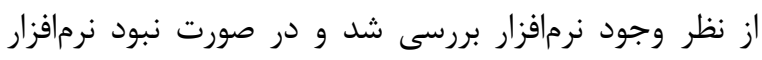

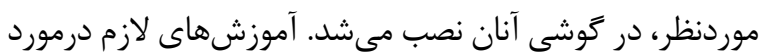




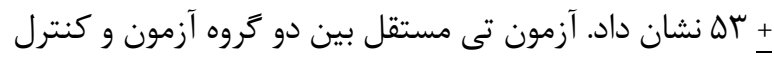

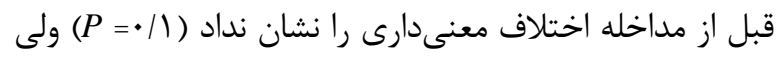

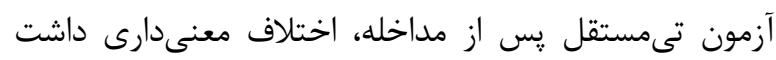

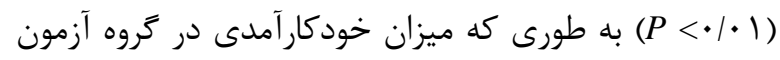

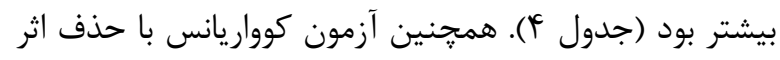

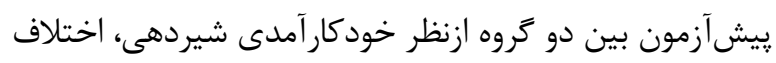

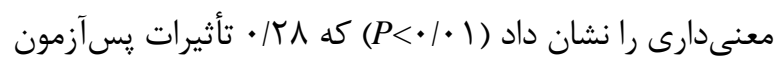

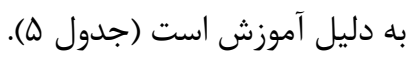

دو گروه آزمون و كنترل اختلاف معنىدارى را نشان داد

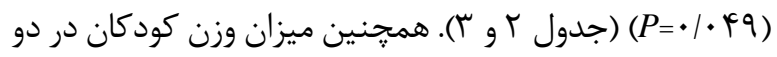

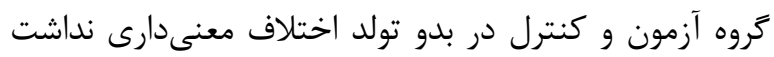

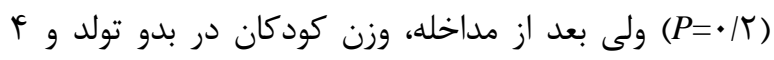

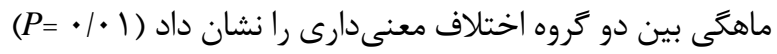

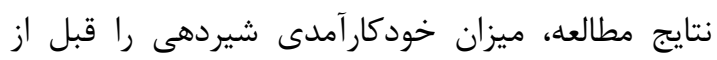

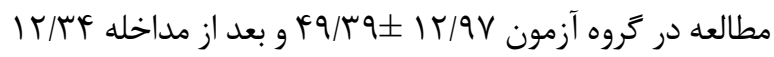

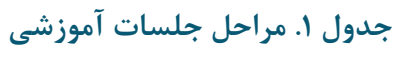

\section{مدت آموزش اهداف آموزشى

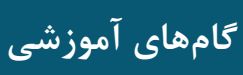

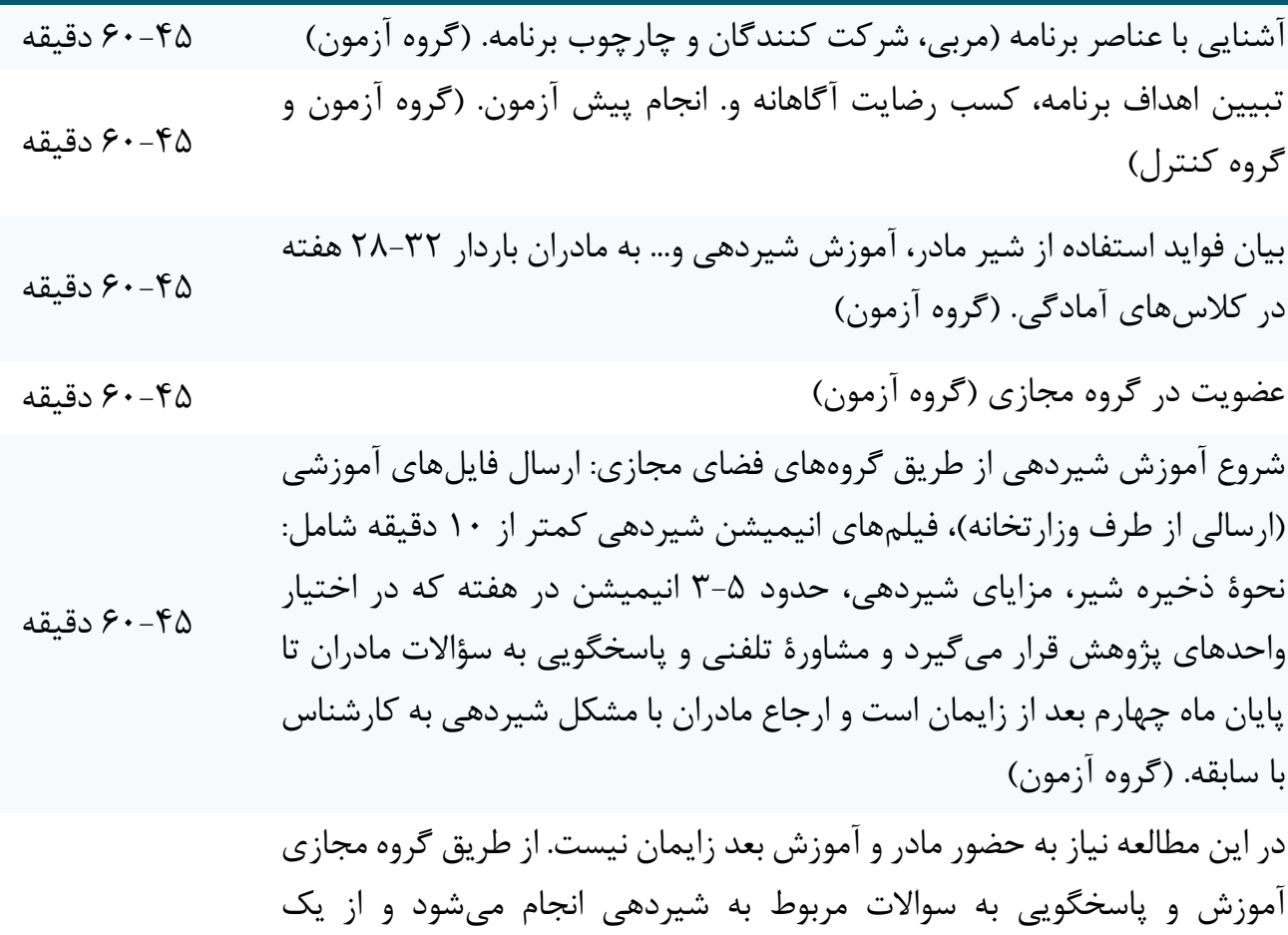

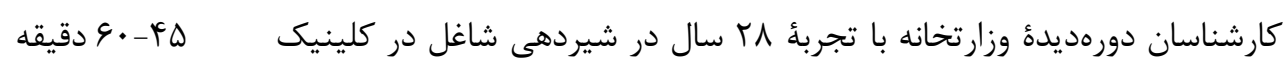

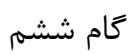

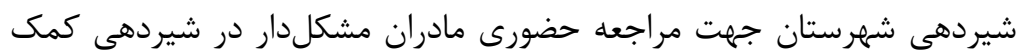

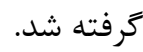
جمعبندى مباحث كذشته و ارائٔ راهكارهايى براى بيگيرى آموختهها، تلاش در

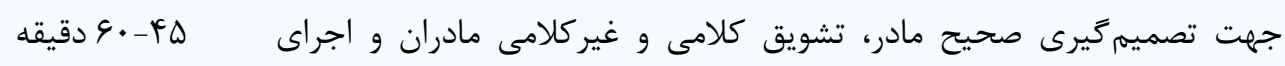

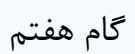
يس آزمون. (كروه آزمون وكروه كنترل). 


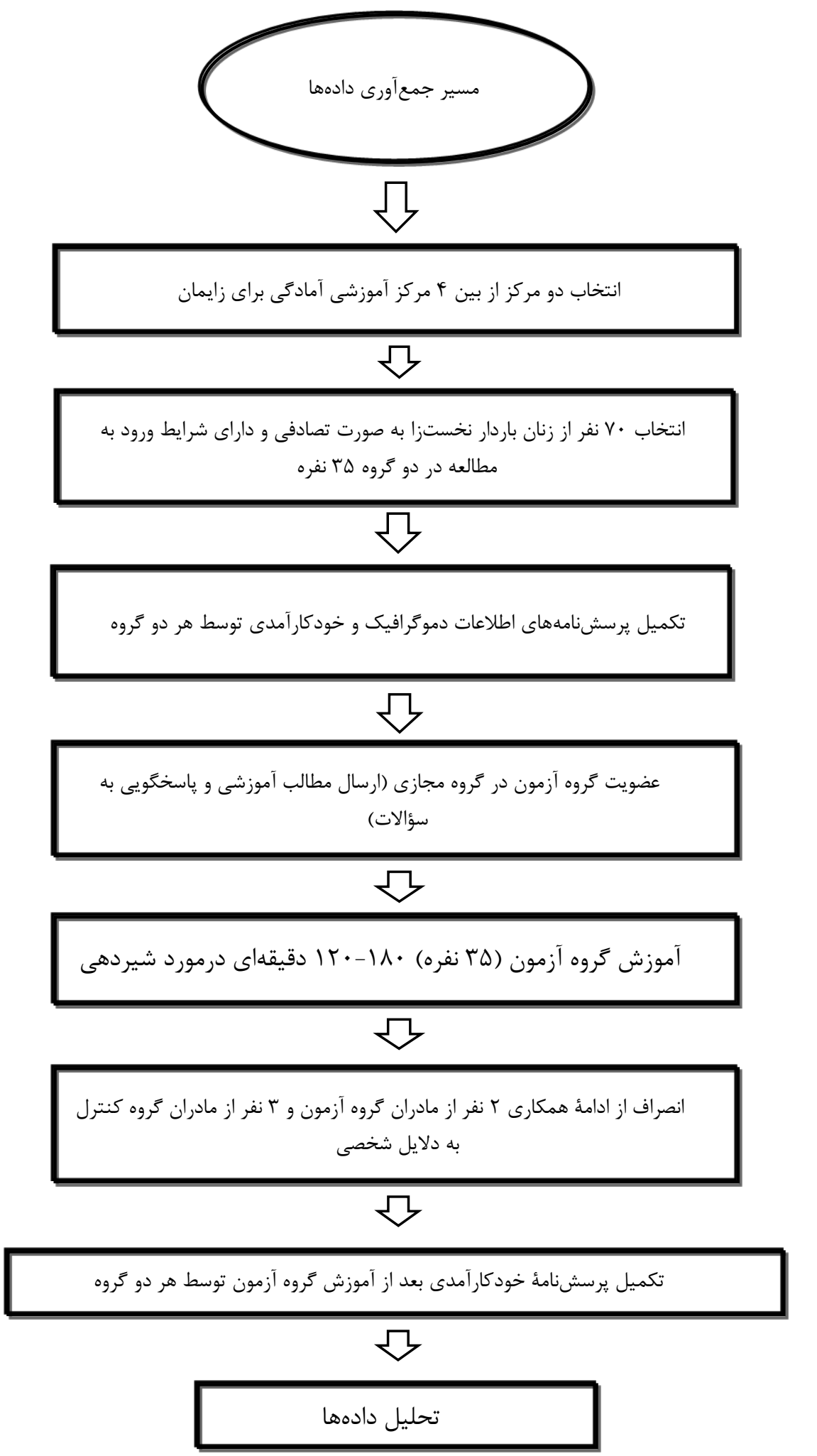

شكل ا. مسير جمع آورى دادهها 
جدول r. مقايسهُ مشخصات دموَّرافيك واحدهاى يُزوهش در دو گروه آزمون و كنترل

\begin{tabular}{|c|c|c|c|c|c|c|}
\hline \multirow{2}{*}{ P-value } & \multicolumn{2}{|c|}{ كنترل } & \multicolumn{2}{|c|}{ آزمون } & \multicolumn{2}{|c|}{ دموكرافيك } \\
\hline & درصد & فراوانى & درصد & فراوانى & & كروه \\
\hline \multirow[t]{3}{*}{$\cdot / T F$} & 11 & re & $r$. & 1 . & 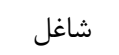 & \multirow{2}{*}{ شغل مادران } \\
\hline & 19 & 4 & $v \cdot$ & r & خانهدار & \\
\hline & 19 & 4 & $r$. & 1 . & كارمند & \multirow{3}{*}{ شغل همسر } \\
\hline \multirow[t]{2}{*}{.119} & & . & 9 & $r$ & كارتر & \\
\hline & 11 & re & 41 & r. & بيكار & \\
\hline \multirow{3}{*}{.1 .9} & 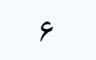 & $r$ & & . & ابتدايى & \multirow{3}{*}{ تحصيلات مادر } \\
\hline & $y_{1}$ & r & rI & v & متوسطه & \\
\hline & $\Delta r$ & IV & vq & rq & دانشَاهى & \\
\hline \multirow{3}{*}{.1 .49} & r & 1 & & . & ابتدايى & \multirow{3}{*}{ تحصيلات همسر } \\
\hline & $\Delta \varphi$ & 11 & $r$. & 1. & متوسطه & \\
\hline & il & rו & $v$. & r & دانشخاهي & \\
\hline
\end{tabular}

جدول r. مقايسُٔ مشخصات دموكر افيك واحدهاى يثوهش در دو كروه آزمون و كنترل

\begin{tabular}{|c|c|c|c|c|c|c|}
\hline \multirow{2}{*}{ P-Value } & \multicolumn{2}{|c|}{ كنترل } & \multicolumn{2}{|c|}{ آزمون } & \multicolumn{2}{|c|}{ دموكر افيك } \\
\hline & انحراف معيار & ميانغين & انحراف معيار & ميانغَين & & كروه \\
\hline$\cdot 10$ & F/9 & TN/GA & $4 / 19$ & TV/QG & 9 rV-19 & سن مادران \\
\hline . IFt & $F / 11$ & $r r / F$ & T/M & rI/99 & JV-rb & سن همسر \\
\hline$\cdot / r$ & .194 & r/qF & $\cdot / f$ & $r / 11$ & زمان تولد & \\
\hline$<\cdot / \cdot 1$ & $.19 \mathrm{~V}$ & $9 / 4 q$ & $V / \cdot V$ & $\cdot / \mathrm{\mu}$ & F ماهكى & \\
\hline
\end{tabular}

جدول F. مقايسُٔ خودكار آمدى مادران قبل و بعد از مداخله در كروه آزمون و كنترل

\begin{tabular}{|c|c|c|c|c|c|}
\hline \multirow{2}{*}{ P-value } & \multicolumn{2}{|c|}{ كنتر ل } & \multicolumn{2}{|c|}{ آزمون } & \multirow{2}{*}{ زمان } \\
\hline & انحراف معيار & ميانغين & انحراف معيار & ميانگين & \\
\hline $\begin{array}{c}P=\cdot / 19 \\
\mathrm{~F}=\cdot / 1\end{array}$ & $1 \pi / 90$ & $F Q / \cdot r$ & $1 r / 9 V$ & $p q / r q$ & قبل از مداخله \\
\hline $\begin{array}{l}P<\cdot / \cdot 1 \\
F=\mid \Delta /{ }^{\prime} F\end{array}$ & $\mathrm{~V} / \mathrm{Vq}$ & $|f| / v 1$ & $I T / M F$ & $\Delta r$ & بعد از مداخله \\
\hline & \multicolumn{2}{|c|}{$P=\cdot / T F$} & \multicolumn{2}{|c|}{$P=\cdot / \Gamma \Delta$} & P-Value \\
\hline
\end{tabular}


جدول ه- مقايسؤ تأثير آموزش از طريق فضاى مجازى بر خودكار آمدى شيردهى مادران

\begin{tabular}{|c|c|c|c|c|c|c|}
\hline Eta & سطح معنى دارى & F & ميانَّين مجذورات & درجةٌ آزادى & مجموع مجذورات & \\
\hline$\cdot / r$ & $<\cdot 1 \cdot 1$ & $\mid r / V \wedge$ & $1 T \Delta N / q 4$ & r & TVIVIA & مدل اصلاحشده \\
\hline .1 .9 & $\cdot 1 \cdot 1$ & 9109 & $9 \Delta \cdot / r q$ & 1 & IGTrG/9T & جداكننده يِ آزمون \\
\hline \multirow[t]{4}{*}{$\cdot / r \Lambda$} & $r F / T Y$ & $Y F / T V$ & $r F \cdot I / V I$ & 1 & $T F \cdot I / V I$ & كروه \\
\hline & & & $9 \wedge / \Delta \Delta$ & GT & $911 \cdot 11 \mathrm{~V}$ & خطا \\
\hline & & & & $9 \Delta$ & IDQI/QT & جمع \\
\hline & & & & $q 4$ & 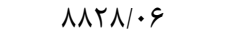 & كل \\
\hline
\end{tabular}

بحث

و مشكل خود را برطرف نمايند؛ اين مزيتى بود كه مطالعُ

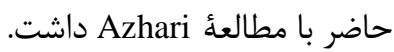
Noel-Weiss

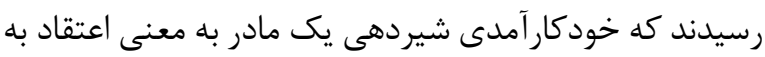
توانيى خود براى شيردهى فرزندش است و ارتباط مثبتى با باديا

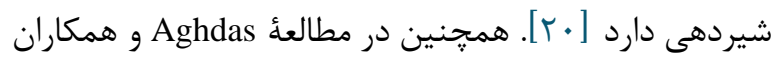

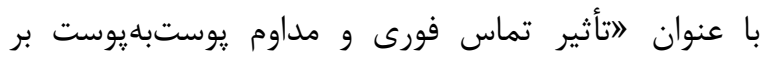
خودكارآمدى شيردهى زنان نخستزاه نشان داده شد كه

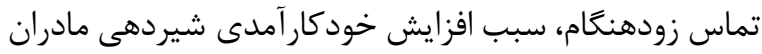

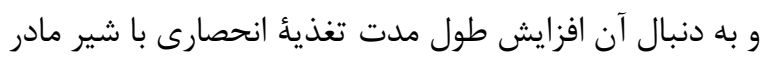

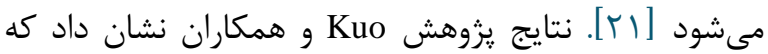

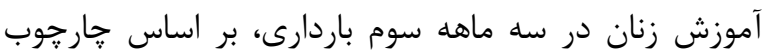

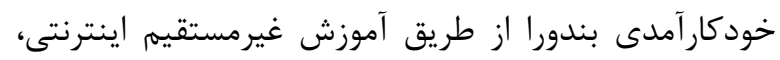

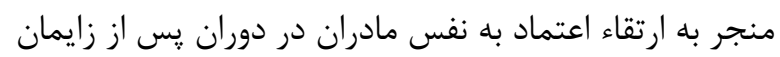

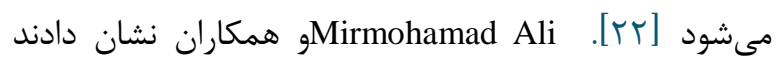

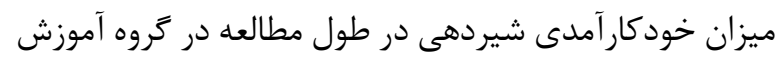

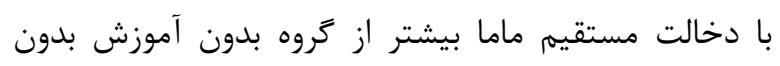

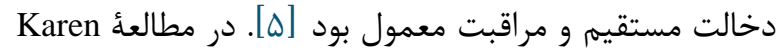

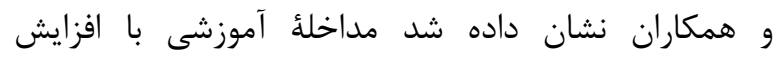

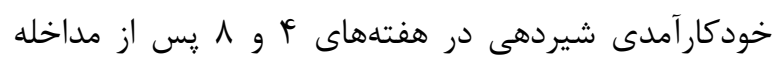

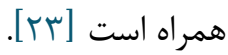
در مطالعه Özkan و همكاران نيز آموزش مراقبت مادر از از

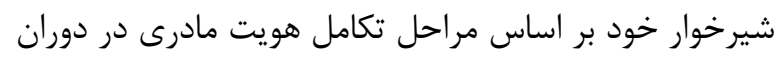

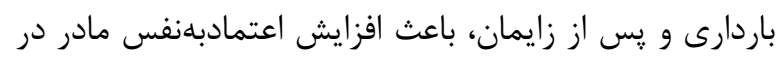

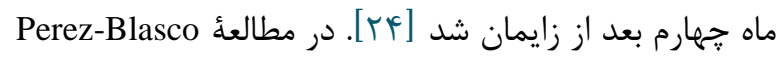

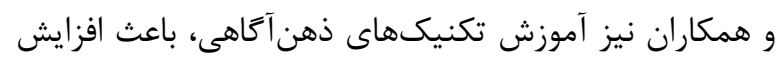
معنادار خودكارآهدى مادرى در مادران شيرده در كَروه مداخله
در مطالعة حاضر، ميزان خودكارآمدى شيردهى در كروه

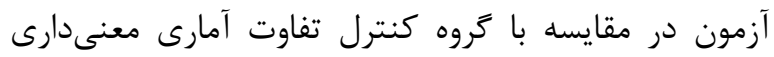

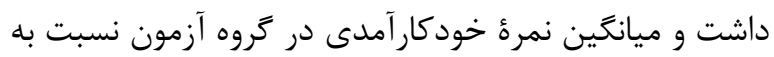

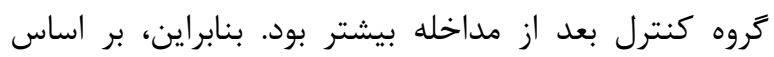

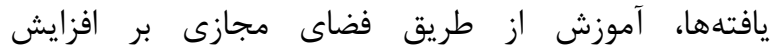

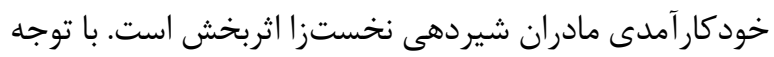

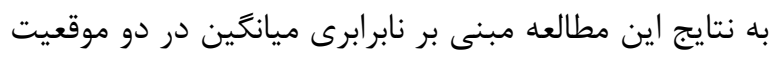

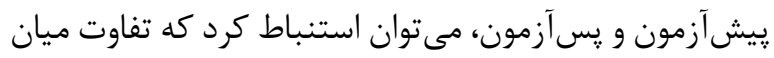

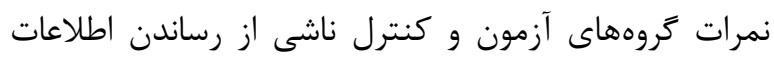

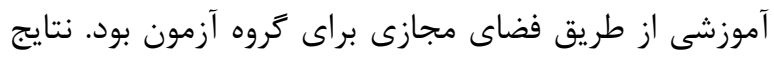

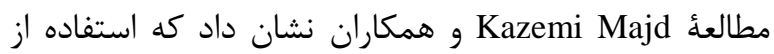

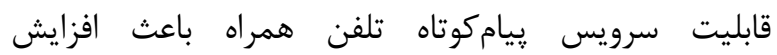

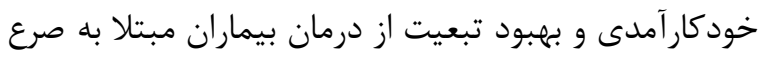

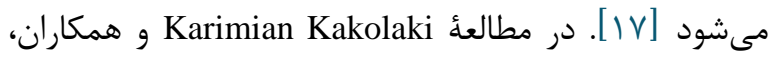
آموزش از طريق شبكهُ مجازى موجب ارتقاى خودكارآمدى

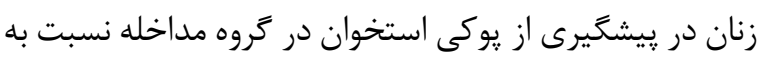

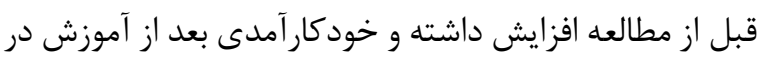
كروه مداخله نسبت به كروه كنترل بيشتر بود [1/1]. مطالعأ Azhari

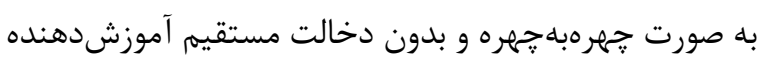

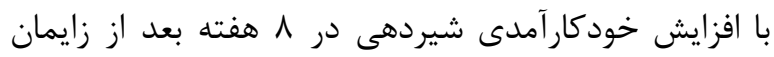

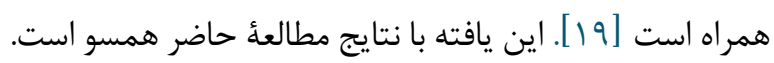

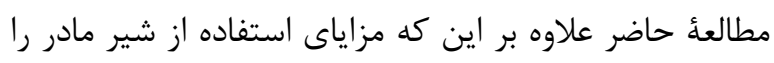

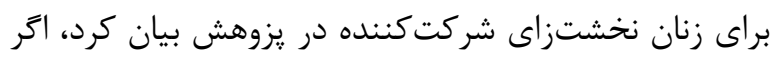

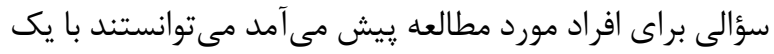

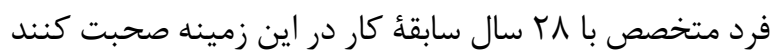


خودكار آمدى شيردهى زنان نخستزا، همراه با ساير روشهاى

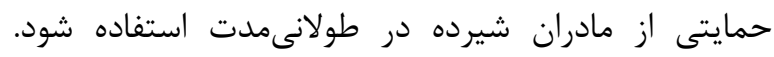

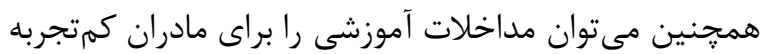

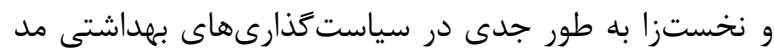
نظر قرار داد.

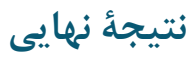

با توجه به نتايج مطالعه و تأثير آموزش از طريق فضاى

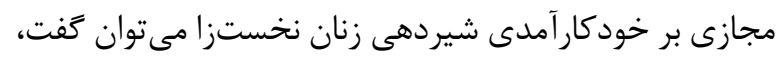

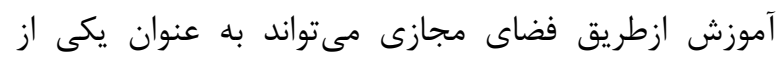
راهبردهاى مؤثر در افزايش خودكارآهدى شيردهى استى إنفادئ

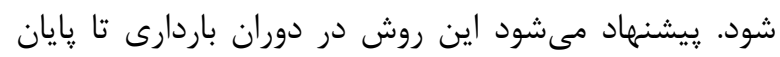

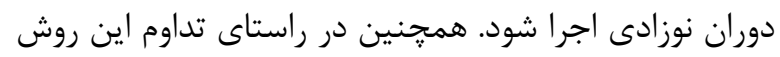

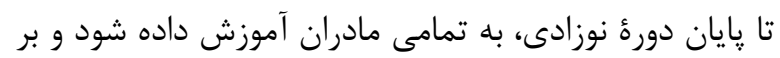

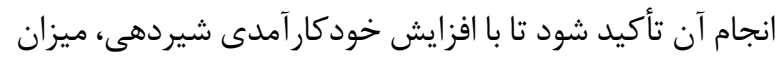
تداوم شيردهى افزايش يابد.

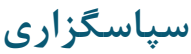

اين مطالعه بركرفته از پاياننامئ مقطع كارشناسىارشد

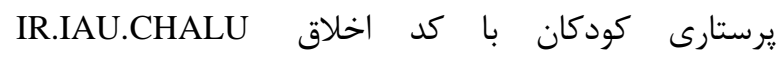

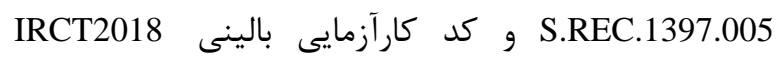

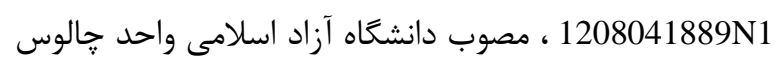

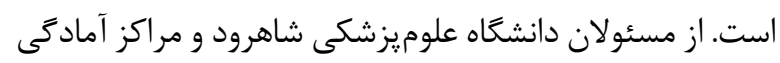

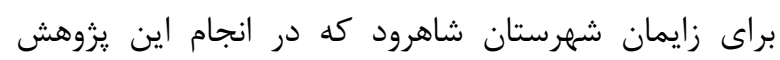
همكارى كردند، كمال تشكر و قدردانى را داريم.

\section{تعارض در منافع}

بين نويسندكان هيجَّونه تعارضى در منافع وجود ندارد

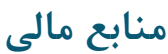

منابع مالى اين مطالعه توسط نويسندًان تامين شده است.

\section{References}

1. Seighali F, Fallahi M, Farahani Z. The effect of breastfeeding workshop on attitude, knowledge and practice of participants. Razi Journal of Medical Sciences. 2014; 21(118):92-101.
نسبت به كروه كنترل شد [ral]. Svensson و همكاران نيز

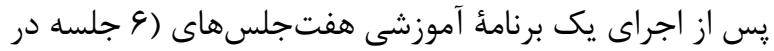
دوران باردارى و يك جلسه در هفته 9 بعد از زايمان) متوجه

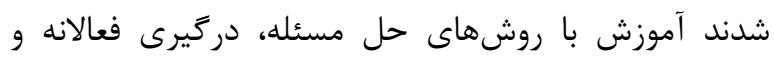

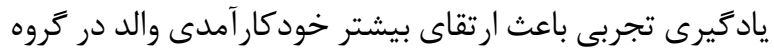

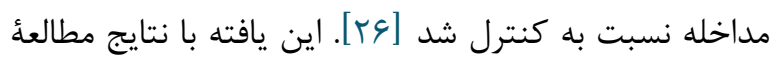

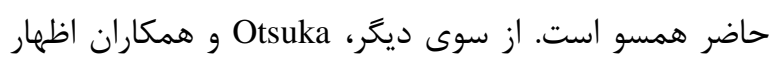

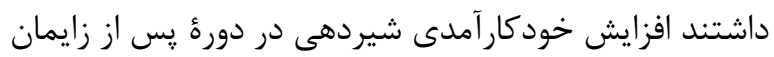

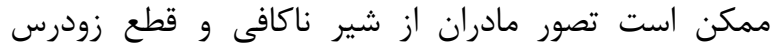

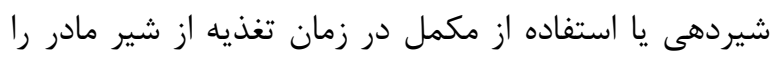

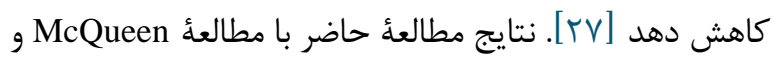

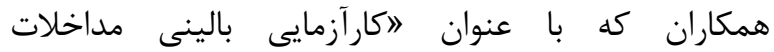

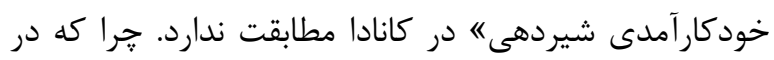

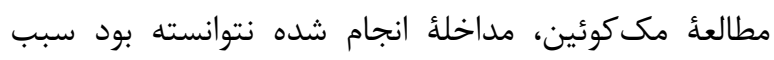
افزايش معنادار خودكارآمدى در زنان نخستزا ماتها شود. مداخلئ

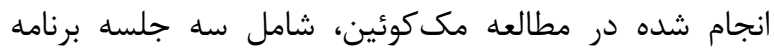

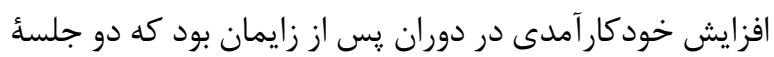

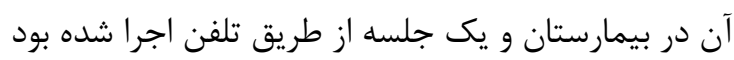

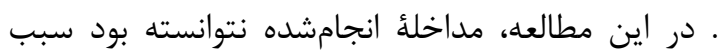

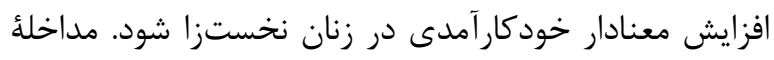

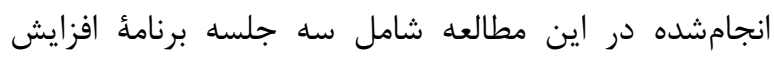

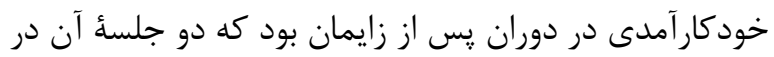

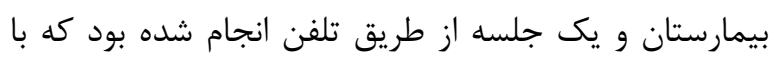

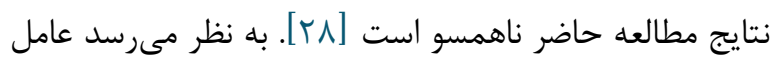

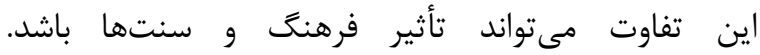
محدوديتهاى اين يزوهش عبارت بودند از اندكبودن حجم فئمان

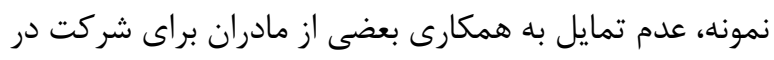

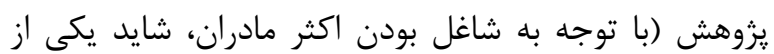

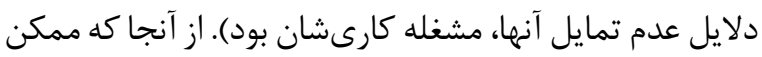

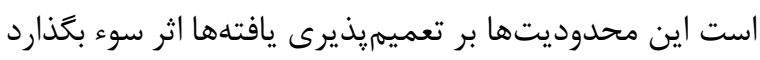

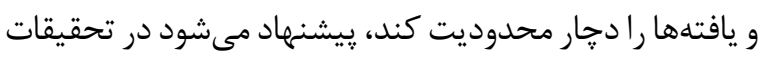

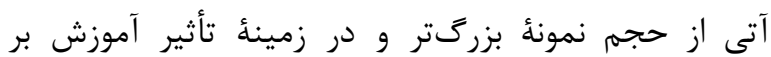

2. Jafari Asl M, Fadakar Sogheh R, Ghavi A, Ahmad Shear Bafi M. Related factors to continued breastfeeding in infants. Journal of Holistic Nursing and Midwifery. 2013; 24(2):1-8. 
3. Demirtas B. Strategies to support breastfeeding: a review. International Nursing Review. 2012; 59(4):474-81. 7657.2012.01017.x] [PMID]

4. Abdollahipour F, Nouhjah S, Latifi SM, Araban M. The impact of applying the breast crawl (TBC) with other educational strategies on breastfeeding self-efficacy after the first breastfeeding among primiparous women in Dezful, Iran. Journal of Health Education and Health Promotion, 2017; 5(1):20-32. [DOI:10.18869/acadpub.ihepsaj.5.1.20]

5. Mirmohamad Ali M, Bahiraee A, Rahimi A, Hashemzadeh M, Sohrabi N, Sohrabi Z. Effect of educational package on breastfeeding self-efficacy in postpartum period. Journal of the Iranian Institute for Health Sciences Research. 2014; 13(2):221-8.

6. Abdeyazdan Z, Elahi T, Golshiri P. Comparison of an empowering breastfeeding program before and after childbirth on exclusive breastfeeding time span. Modern Care, Scientific Quarterly of Birjand Nursing and Midwifery Faculty. 2015; 11(4):330-8.

7. Parsa P, Boojar A, Roshanaei G, Bakht R. The effect breastfeeding counseling on self-efficacy and continuation breastfeeding among primiparous mothers: a randomized clinical trial. Scientific Journal of Hamadan Nursing \& Midwifery Faculty, 2016; 24(2):98-104.

8. Carlson Bowles B. Promoting breastfeeding selfefficacy: fear appeals in breastfeeding management clinical lactation. Clinical Lactation. 2011; 2(1):11-4. [DOI:10.1891/215805311807011782]

9. Moafi F, Hajnasiri H, Hosseini T, Alimoradi Z, Bajalan $Z$. Breastfeeding self-efficacy and its associated factors in women who gave birth in Kosar Hospital of Qazvin in 2016-2017: A descriptive study. Journal of Rafsanjan University of Medical Sciences, 2019; 17(11):1003-16.

10. Sinsuksai N, Nuampa S, Chanprapaph P. Factors predicting 6-month-exclusive breastfeeding in mothers with cesarean section. Journal of Nursing Science. 2017; 35(1):14-22.

11. Capurro D, Cole K, Echavarría MI, Joe J, Neogi T, Turner AM. The use of social networking sites for public health practice and research: a systematic review. Journal of Medical Internet Research. 2014; 16(3):e79. doi: 10.2196/jmir.2679 [DOI:10.2196/jmir.2679] [PMID] [PMCID]

12. O'Brien SJ. Facebook and other internet use and the academic performance of college students. Philadelphia: Temple University; 2011.

13. Moghaddam F, Norouzi S, Sharafi F. Explore Experiences Students of Social Networks and Their Impact on Lifestyle. Iranian Journal of Nursing Research. 2016; 11(3):66-73.

14. Fatehi F, Malekzade G, Akhavimirab A, Rashidi M, Afkhami Ardekani M. The effect of short message service on knowledge of patients with diabetes in Yazd, Iran. Iranian Journal of Diabetes and Obesity. 2010; 2(1):27-31.
15. Kohan S, Heidari Z. The effect of family-oriented educational-supportive programs on adequacy of exclusive breastfeeding from the perspective of mothers. Journal of Babol University of Medical Sciences, 2017; 19(1):53-8.

16. Araban M, Falahiyan Mehrjardi F, Shahry P, Montazeri A. The Persian version of Breastfeeding Self-Efficacy Scale-Short Form (BSES-SF): translation and psychometric assessment. Payesh, 2016; 15(1):87-93.

17. Kazemi Majd R, Hosseini MA, Hadi Safi M, Norouzi $\mathrm{K}$, Hoseinzadeh S. The effect of self-care education based on short message service on self-efficacy and adherence to the medication regimen in adolescents with epilepsy referred to Iran Epilepsy Association of in 2016. Journal of Nursing Education. 2017; 4(3):4854.

18. Karimian Kakolaki Z, Eslami AA, Gerayllo S, Heidari F, Safari Hajataghaie S, Behzadi Goughari S. Effect of education using the virtual social networks on promoting women's self-efficacy in preventing osteoporosis. Journal of Education and Community Health. 2018; 5(3):57-62. [DOI:10.21859/jech.5.3.57]

19. Azhari S, Baghani R, Akhlaghi F, Ebrahimzadeh S, Salehi Federdi J. Comparing the effect of hands - on and hands off breastfeeding methods on self - efficacy in primiparous mothers. Journal of Sabzevar University of Medical Sciences and Health Services. 2011; 17(4):248-55

20. Noel-Weiss J, Bassett V, Cragg B. Developing a prenatal breastfeeding workshop to support maternal breastfeeding self-efficacy. Journal of Obstetric, Gynecologic, and Neonatal Nursing. 2006; 35(3):34957. [DOI:10.1111/j.1552-6909.2006.00053.x] [PMID]

21. Aghdas K, Talat K, Sepideh B. Effect of immediate and continuous mother-infant skin-toskincontact on breastfeeding self-efficacy of primiparous women: a randomised control trial. Women and Birth. 2014; 27(1):37-40. doi: $10.1016 /$ j.wombi.2013 [DOI:10.1016/j.wombi.2013.09.004] [PMID]

22. Kuo SC, Chen YS, Lin KC, Lee TY, Hsu CH. Evaluating the effects of an Internet education programme on newborn care in Taiwan. J Clin Nurs 2009 Jun;18(11):1592-601. [DOI:10.1111/i.13652702.2008.02732.x] [PMID]

23. Karen A. A pilot randomized controlled trial of a breastfeeding self-efficacy. Journal of Obstetric, Gynecologic, \& Neonatal Nursing. 2010; 40(1):35-46. [DOI:10.1111/j.1552-6909.2010.01210.x] [PMID]

24. Özkan H, Polat S. Maternal identity development education on maternity role attainment and my baby perception of primiparas. Asian Nursing Research. 2011; 5(2):108-17. [DOI:10.1016/S19761317(11)60019-4]

25. Perez-Blasco J, Viguer P, Rodrigo MF. Effects of a mindfulness-based intervention on psychological distress, well-being, and maternal self-efficacy in breast-feeding mothers: results of a pilot study. Archives of Women's Mental Health. 2013; 16(3):22736. [DOI:10.1007/s00737-013-0337-z] [PMID] 
زينب حيدرى و همكاران هTr

26. Svensson J, Barclay L, Cooke M. Randomisedcontrolled trial of two antenatal education programmes. Midwifery. 2009; 25(2):114-25. [DOI:10.1016/j.midw.2006.12.012] [PMID]

27. Otsuka K, Dennis CL, Tatsuoka H, Jimba M. The relationship between breastfeeding self-efficacy and perceived insufficient milk among Japanese mothers. Journal of Obstetric, Gynecologic, \& Neonatal Nursing. 2008; 37(5):546-55. [DOI:10.1111/j.15526909.2008.00277.x] [PMID]

28. McQueen KA, Dennis CL, Stremler R, Norman CD. A pilot randomized controlled trial of a breastfeeding selfefficacy intervention with primiparous mothers. Journal of Obstetric, Gynecologic, \& Neonatal Nursing. 2011; 40(1):35-46. [DOI:10.1111/j.15526909.2010.01210.x] [PMID] 